\title{
AC 2008-2356: EXPERIENCES IMPLEMENTING AN UNDERGRADUATE CIVIL ENGINEERING COURSE IN BIM
}

Matthew Dupuis, University of Wisconsin - Madison

Benjamin Thompson, University of Wisconsin - Madison

Lawrence Bank, University of Wisconsin - Madison

John Herridge, Autodesk 


\section{Experiences Implementing an Undergraduate Civil Engineering Course in BIM}

\section{Introduction}

The use of Building Information Modeling (BIM) is causing fundamental changes in the AEC (Architecture/Engineering/Construction) industry ${ }^{1,2}$. Numerous organizations are putting forth their definitions of $\mathrm{BIM}^{3,4,5}$ and multiple software vendors are marketing BIM software packages. But BIM is not as simple as a new software package for designers; it is quite literally a paradigm shift in the concept of building delivery and operation. The BIM design methodology combined with the software allows all the design professionals, from all disciplines and trades, to contribute knowledge and share it in one three dimensional parametric model. Once the design team is finished the contractors can use this same model to do quantity extractions, estimating, construction planning and even computer aided manufacturing. During owner operation of the building, this model can be used for facility management and planning. The use of BIM can eliminate the reliance on rolls of two dimensional drawings and the inherent loss of information and efficiency when these drawings are transferred from member to member of the AEC team. This method of building delivery appears to be as revolutionary to the AEC industry as computer aided manufacturing and robotics were to the automotive industry.

Many major architecture, engineering and contracting firms have begin to shift entire offices or their whole operation to the BIM methodology ${ }^{2}$. For engineering graduates to be marketable and competitive in the job market of the near future, experience with BIM software and knowledge of the BIM design and delivery methodology will be increasingly important.

Therefore, in the spring semester of 2007, the University of Wisconsin at Madison offered its first two-credit engineering elective course in Building Information Modeling (BIM) to undergraduate (and a few graduate) students in the Civil and Environmental Engineering (CEE) Department. The course was added to the spring timetable late in November 2006 as a special topics "experimental" offering to gage the student interest in this technology and to introduce the topic on a trial basis into the CEE curriculum. Since the course was added late to the previously published timetable for the Spring semester the course was advertised by email to CEE students only in early December of 2006 as a limited enrollment course for 20 students. Prior to advertising the course the department had not explicitly discussed BIM with students in formal courses in the department. Student response to the new course offering was very strong. Within three days all 20 slots had been filled. Clearly the students were aware something was happening in the AEC (Architecture/Engineering/Construction) industry with BIM and were eager to learn about the technology. The second time the course was offered in the fall semester of 2007, the student response was similar. The course will be offered for a third time in the spring of 2008. For all three offerings of the course the only prerequisite was the introductory drafting course taught in the College of Engineering at the University of Wisconsin at Madison.

The purpose of this paper is to report on the lessons learned from developing a curriculum, homework, and readings and teaching a BIM course to Civil and Environmental Engineering students, so that other departments might learn from our experiences and tap into a growing demand for a BIM knowledge base in our graduates and in the AEC industry at large. The paper 
will discuss the way in which the curriculum was developed, why various curriculum elements were included, how the students were motivated, how the students' development and performance in the course were assessed, what the instructors learned from students and practitioners while teaching the course, and how this learning is being used to improve the course as it moves forward.

\section{Course Inception}

The rapidly increasing importance of Building Information Modeling in the AEC industry was becoming increasing clear to a number of the CEE faculty at the University of Wisconsin Madison (UW) in the years preceding the introduction of the course. Key faculty in the Structural and Construction Engineering groups were closely following trends in the AEC industry, and through a variety of course offerings, were seeing the use of 3D CAD and 4D simulation tools emerging in student projects. A key course in this respect was the AEC Global Project Course (see http://pbl.stanford.edu/ClassWeb2008/Experiences/exp.htm) offered by Stanford University in which UW students and faculty mentors have participated since spring 2005. In this hands-on project course student teams consisting of architects, structural engineers and construction engineers design a 30,000 sq. $\mathrm{ft}$. building in cyberspace using state-of-the art modeling, simulation and communication tools. 3D architectural and structural modeling tools have been used in the course since the early 2000s. These tools primarily included AutoCAD (http://usa.autodesk.com) for drafting, a solid form modeling software called Bentley TriForma (http://www.bentley.com/en-US/Products/MicroStation/MicroStation+TriForma.htm), ETABS (http://www.csiberkeley.com/products ETABS.html), which is a design and analysis tool for buildings, SAP2000 (http://www.csiberkeley.com/products_SAP.html) and RISA-3D (http://www.risatech.com/risa-3d.asp) for structural analysis, and Commonpoint 4D (http://www.commonpointinc.com/), a construction planning software tool. BIM tools (primarily REVIT Building/Architecture and Bentley Architecture) started appearing in the class projects in the spring of 2006 and took hold firmly in the spring 2007 course. Students in the AEC Global Project Class generally had minimal exposure to these software tools (with the exception of AutoCAD and one of the structural analysis tools) before beginning the class. In addition to class trends, two of the authors attended a Building Technologies Workshop at Oak Ridge National Laboratory in February 2006 and a BIM in Structural Engineering Workshop organized ay SEI/ACEC in July 2006.

By the fall of 2006, the conditions and interest level among key faculty were sufficient to offer a course at the University and the CEE Department sought a means to do this given that individually its members did not have the technical expertise to offer a formal course in BIM to its students. In addition, intellectual questions were raised about the form that such a universitylevel course would take. It must teach the students more than the hands-on skill set for "how to use" a BIM program. It was agreed that this would not be a sufficient intellectual challenge for the students, nor of a sufficiently collegiate academic nature.

Fortunately for the UW, Autodesk had just launched their Autodesk Student Community (http://students.autodesk.com) and was promoting the use of BIM in universities throughout the United States. However, for the AEC portion of the Student Community, the primary focus appeared to be in Schools of Architecture and not in Schools of Engineering. Although Autodesk 
appeared interested in introducing BIM to engineering students, their focus was initially on the structural engineering side through the REVIT Structure program. A meeting in November 2006 with the Autodesk Academic Programs Manager led to an offer from Autodesk to provide handson training in a series of bi-monthly visits to the campus from one of the authors who serves as the Autodesk Worldwide Education Program Building Solutions Specialist. With this agreement in place the course was hastily offered to students via an email announcement described earlier. The next challenge was to develop the curriculum that would encompass the intellectual and academic aspects the department had been grappling with. In January 2007, one of the authors attended a local BIM seminar sponsored by Master Graphics (http://www.masterg.com/softwaresolutions/building-aec), a local Autodesk reseller. At this seminar contact was made with many local industry BIM practitioners (architects, structural engineers and construction engineers) who expressed their willingness to be engaged as guest speakers in the recently scheduled BIM class.

\section{Course Curriculum Development}

Although not explicitly formulated at the time, the discussion on how to achieve the broader intellectual and academic goals focused on student learning objectives and instructor learning objectives. The student learning objectives can be categorized into four main topic areas.

The first group of student learning objectives were those focused on the process and potential of BIM, as opposed to merely the use of BIM. This included the concept of what really constitutes BIM, as opposed to more traditional three-dimensional modeling. It was a main goal of the course to impress upon the students that BIM is about computable information. The course was also designed as a way for students to understand the difference between BIM tools and BIM processes, and to understand that without the appropriate process changes, the tools can not reach their full potential. As such, another student learning objective was to use BIM as a means of enhancing CEE student understanding of all aspects of building construction (e.g., architectural, structural, MEP, materials, scheduling, estimating, planning, project delivery methods, simulation, and marketing).

The second group of student learning objectives consisted of exposing students to the state of the practice in the AEC industry concerning BIM. This included teaching the students the value and opportunities that BIM brings to the AEC industry, teaching students to identify the importance of and the limitations of BIM in current and future AEC practice, and teaching students to listen attentively to industry practitioners and to evaluate the use of BIM tools in current professional AEC practice in an objective manner.

The next group of student learning objectives focused on the technical aspects of BIM. These included teaching CEE students to use BIM software programs for a variety of AEC related tasks, and teaching students to use BIM models intelligently and to understand how they interface with other 3D, 4D and 5D modeling techniques used or emerging in the construction industry.

The final group of student learning objectives were more academic in nature and included teaching students to read current technical literature in a rapidly evolving discipline, to make 
informed judgments of these sources, and to independently research a specific topic in BIM technology and present results in a written and oral form.

Instructor learning objectives revolved around learning how to deliver a course to CEE students on new, rapidly evolving technologies and processes in AEC practice. The instructor objectives included learning how to create a curriculum without a reference textbook, how to work with local industry to create a collaborative learning environment that has value to all parties, how to motivate students to explore the meaning of BIM beyond learning how to "use" a BIM modeling program, how to assess student learning of BIM and to measure their intellectual growth in the subject throughout the semester, and how to offer the course in a sustainable fashion without the aid of external instructors to teach the hands-on aspects of the course. In addition, the instructors intended to learn about the current BIM practices in the AEC industry. These objectives were to learn how and why the local AEC industry is implementing BIM today and help them to understand the potential and limitations of the technology, and finally to learn what the local and national/international AEC industry needs from graduating CEE students in terms of BIM understanding and tools.

In order to realize these student and instructor learning objectives, multiple types of activities were deemed necessary. The first offering of the course included the following activities:

- Bi-monthly hands-on computer face-to-face laboratory sessions with an Autodesk professional to teach the student to build models using Revit Building 9 and Revit Structure 3;

- Bi-monthly in-class laboratory sessions where students worked on their models and reviewed modeling techniques;

- An electronic forum where students were able to post questions and receive answers from the Autodesk professional;

- Bi-monthly presentations by leading local BIM users including owners, architects, structural engineers and construction engineers;

- Weekly technical reading assignments requiring students to read, review and answer questions on various BIM topics; and

- A final project in the last four weeks of the semester that required students to work in groups and research a BIM API (application program interface) or related program, write a report and make a group presentation.

The versions of Revit used to teach the students were available at the university as part of an existing system-wide Autodesk license. The most current versions of these products are known as Revit Architecture 2008 and Revit Structure 2008, respectively (in addition to Revit Systems 2008). Each of the course activities listed above is described in more detail in what follows.

\section{BIM Modeling Work}

The hands on modeling work for the course was divided into different AEC disciplines and focused on the use of the Revit programs for three key civil engineering disciplines: architecture (Revit Building 9), construction management (Revit Building 9) and structural engineering (Revit Structure 3). A mechanical systems module using Revit Systems 1 was added in the fall 
2007 semester as an experiment by the instructors. A textbook was not assigned for the course; however the students were provided with a copy of the Autodesk instructor lesson notes ${ }^{6}$ and the Autodesk Revit Users guides ${ }^{7}$ as resources.

The architecture component of the course covered the fundamentals of Revit modeling such as grids, levels, importing and using 2D CAD files, conceptual design, building envelopes, building components, visualizing design data, parametric objects, object types, and object properties. The construction management component covered such topics as material schedules, product schedules, cost estimation, construction simulation, walk-throughs and phasing. The structural engineering component covered the fundamentals of Revit Structure, import/export of Revit building models, differences between architectural and structural objects, levels, offsets, exporting to a structural analysis program (RISA or RAM), and structural loads. For the mechanical systems module, added in fall 2007, the instructors covered very basic items such as creating ductwork, air handling units, variable-air-volume (VAV) boxes and diffusers.

In order to make the modeling example more meaningful and realistic for the students, the North wing of a new campus dormitory building, Ogg Hall, was used as the modeling example for most of the Revit exercises. Through discussions and close cooperation with the university Facilities Planning and Management (FPM) department, both PDF and AutoCAD versions of the entire set of construction documents were obtained so that the Revit models developed would be accurate. The use of the same plans by all the students was crucial in the grading process, to set a standard. Discrepancies and errors in the student's modeling homework submissions usually resulted from misinterpretation of 2D plans or misuse of an object; such as stair treads not aligning with the landing. The building and a Revit model from a similar viewpoint are shown in Figure 1.

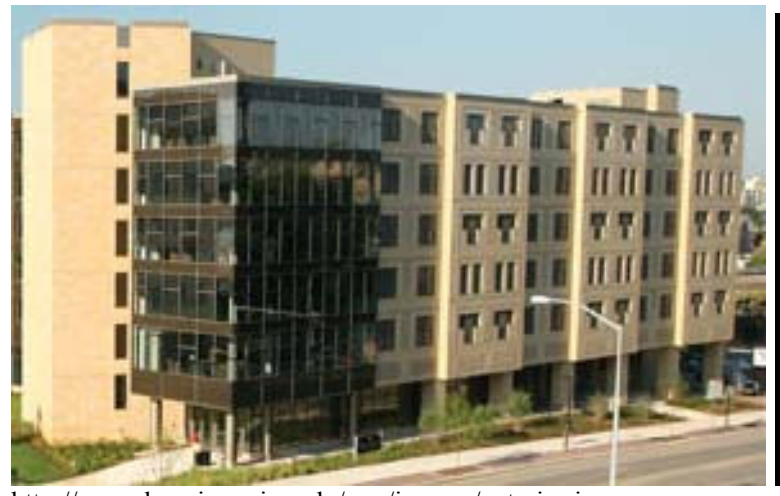

http://www.housing.wisc.edu/ogg/images/exterior.jpg

(a)

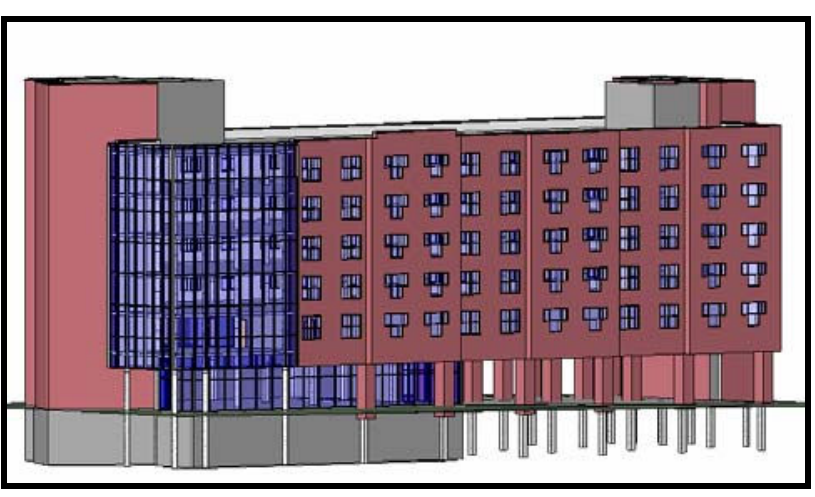

(b)

Figure 1. (a) Case Study Building (b) Revit Model of Building

Six student Revit homeworks were assigned, each dealing with a different aspect of Revit. For each assignment the instructor would post a Revit "start-file" for the model so that all students started each week from the same point. This simplified the grading, as students were not using their own previous model, which may have contained unique flaws, which could then propagate 
through subsequent assignments. This allowed the instructors to independently gage each assignment and eliminated cumulative errors by students.

The order of topics was switched slightly for this second offering of the course. In the spring semester of 2007 architectural topics were covered first, followed by construction management (CM) topics and then structural. For the second offering of the course, in the fall, lessons were arranged with architectural topics followed by structural and then by an added mechanical, electrical and piping (MEP) assignment, and finishing with CM topics. This arrangement offered a chance to illustrate the way a model or model information would typically flow between project participants in an industry BIM project. Assignments 1, 2, 3 and 6 required students to use Revit Building 9. Assignment 4 used Revit Structure 3, and Assignment 5 used Revit Systems 1. The homework assignments dealing with architectural and construction management topics used the previously mentioned north wing of Ogg Hall on the UW-Madison campus.

The first assignment consisted of simply reproducing the gridlines and levels for the Ogg Hall building. This first assignment was intended to familiarize the students with the plans of the building and with navigating the Revit program.

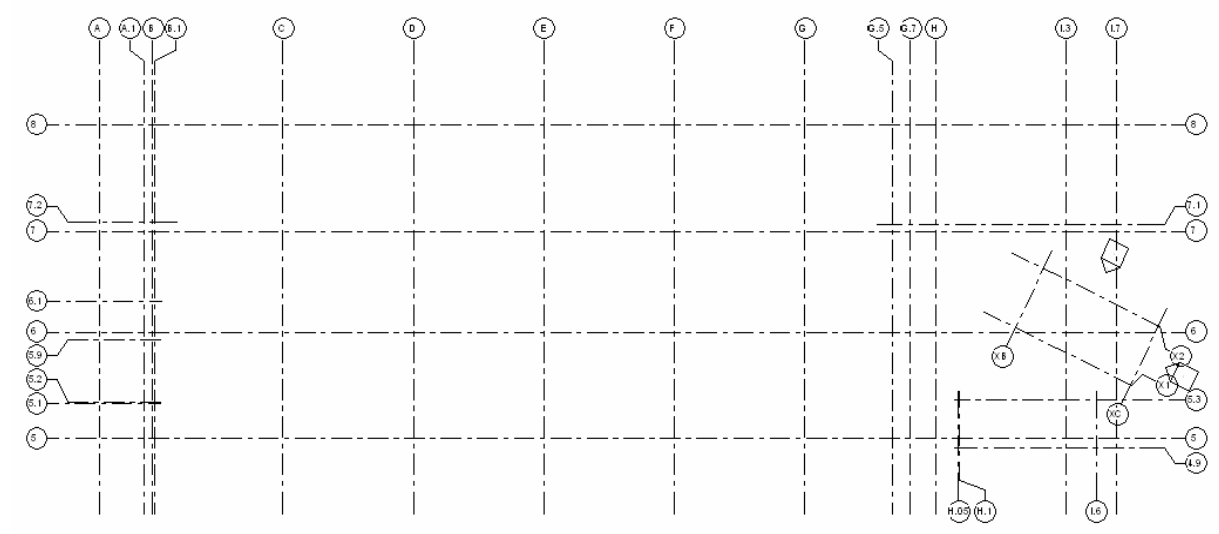

Figure 2. Assignment 1- Revit Building, Grid Lines and Levels.

The second assignment required the students to complete the exterior shell model of the Ogg Hall building by consulting the appropriate plan sheets. This assignment included adding walls, curtain walls, exterior doors, windows, roofs, and architectural columns, as well as interior floors. 


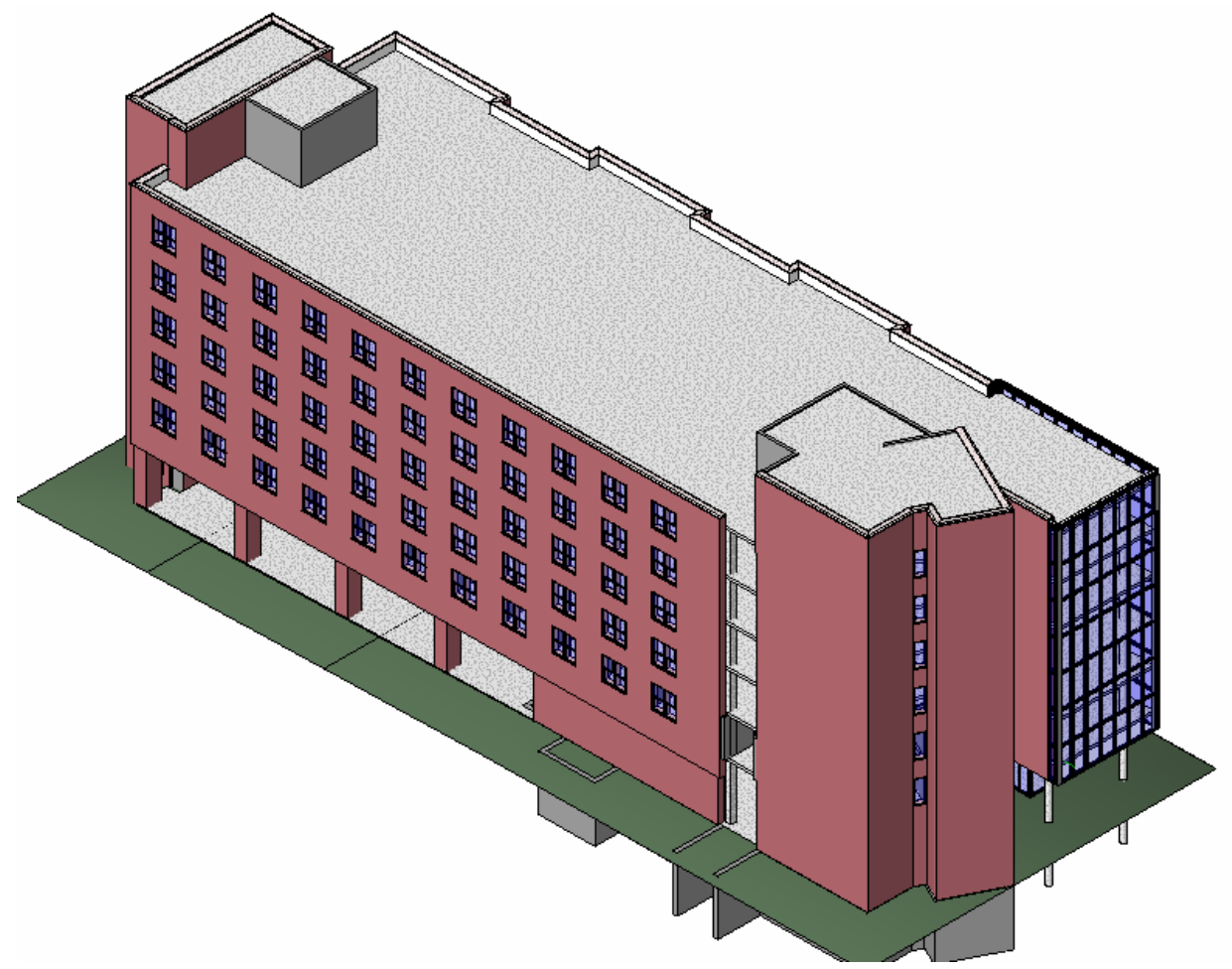

Figure 3. Assignment 2 - Revit Building, Exterior.

In assignment 3, students added ceilings and interior walls to the Ogg Hall building. Also included in this lesson were other interior components, such as interior doors, stairs, and plumbing fixtures. Different types of views were also examined in this assignment, by requiring the creation of various section views in the Revit file.

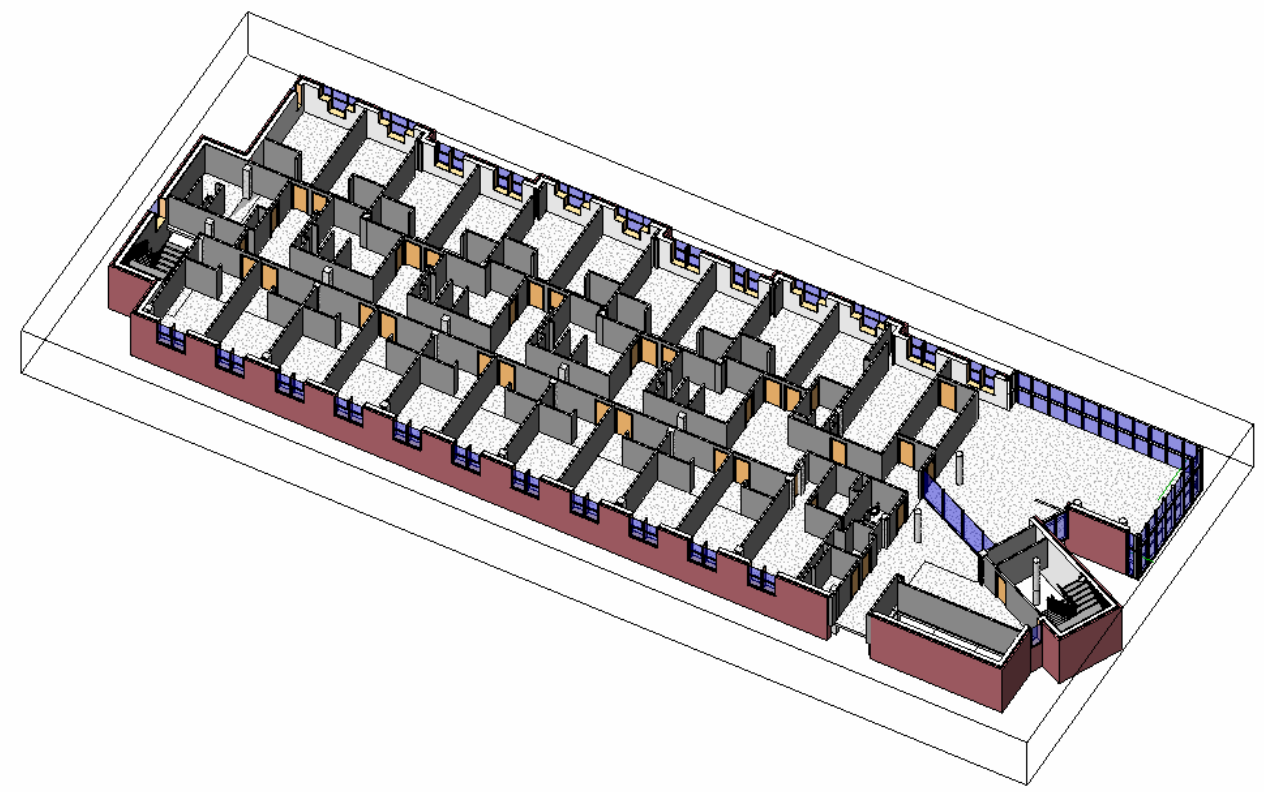

Figure 4. Assignment 3 - Revit Building, Interior. 
Assignment 4 was a basic exploration of Revit Structure 3. To keep this assignment simple and to apply the concepts the instructors emphasized in using Revit Structure, a basic hypothetical building was developed (see Figure 5). The tasks for this assignment included placing structural footings, columns, girders, beams, beam systems, and slabs, and then assigning sample loads to members. Once the members and loads were placed, students were required to create a drafting sheet showing a plan, section, elevation, and 3D view in Revit Building 9. Therefore, students were required to explore the concept of importing a Revit Structure file into the Revit Building program.

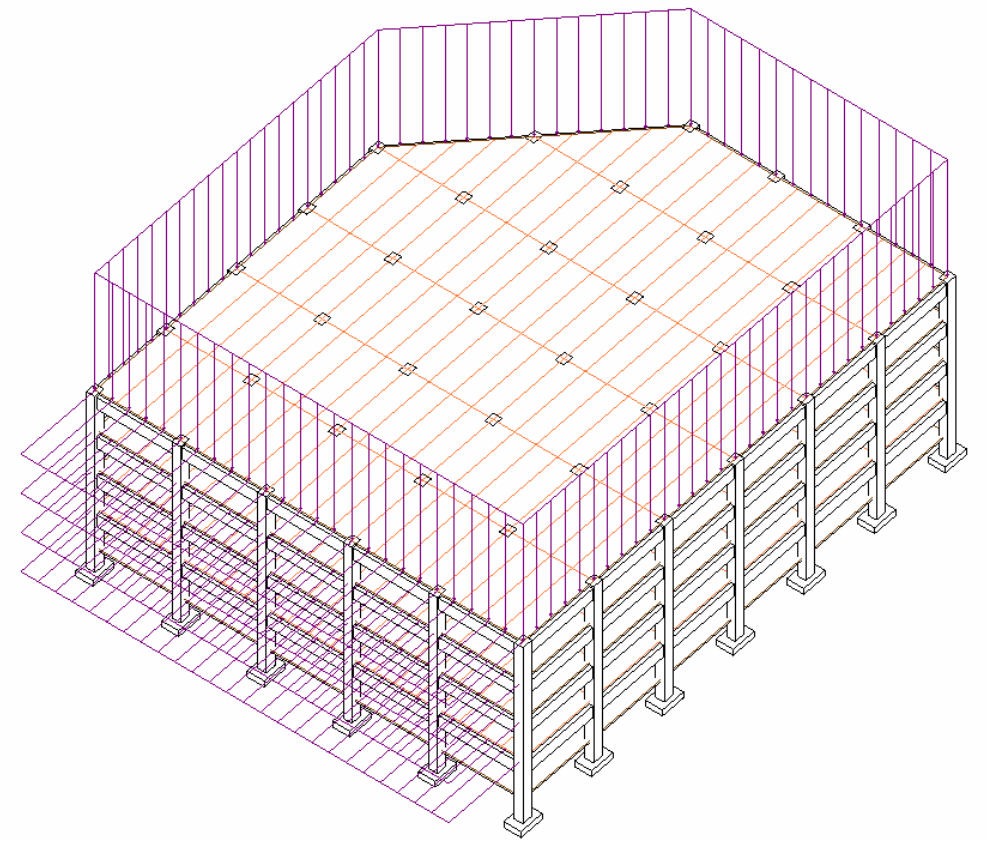

Figure 5. Assignment 4, Revit Structure.

Homework 5 was designed to give the students exposure to the mechanical systems of a building and create an appreciation for the coordination functions available in the Revit family of programs. For this assignment, students were required to place a supply air system, including diffusers, VAV boxes, duct systems, and vertical duct runs leading to a rooftop air conditioning unit. A training file from the Revit Systems program was modified for use as the base model for this homework. Again, the assignment was kept extremely simple, as only one class period was dedicated to the Revit Systems overview. 


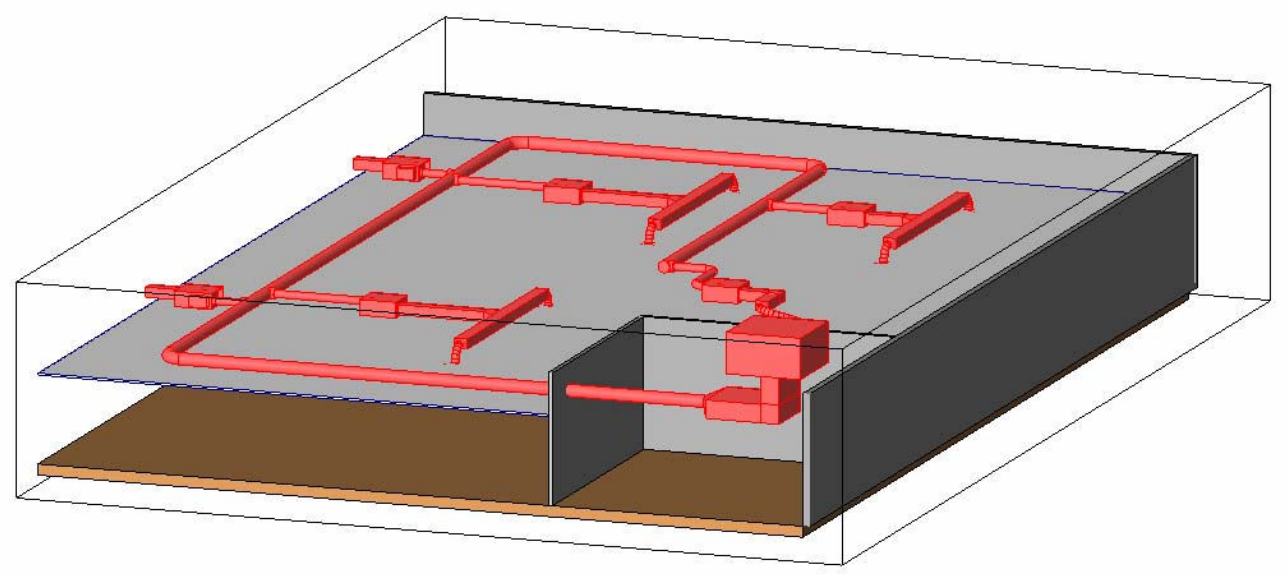

Figure 6. Assignment 5 - Revit Systems

Finally, the sixth assignment returned to Ogg Hall and Revit Building to give the students exposure to the construction management features of Revit Building 9. In this assignment, students created rooms and added room tags to the model completed in Assignment 3. After room tags were added they were required to create a room schedule, door schedule and window schedule. By adding costs to the window objects, the window schedule was used to create a simple fenestration cost estimate, which the students then exported to an Excel file. Finally, the students were required to create a simple phasing for the Ogg Hall construction using Revit Building 9. An example of the phasing steps and output is shown in Figure 7.
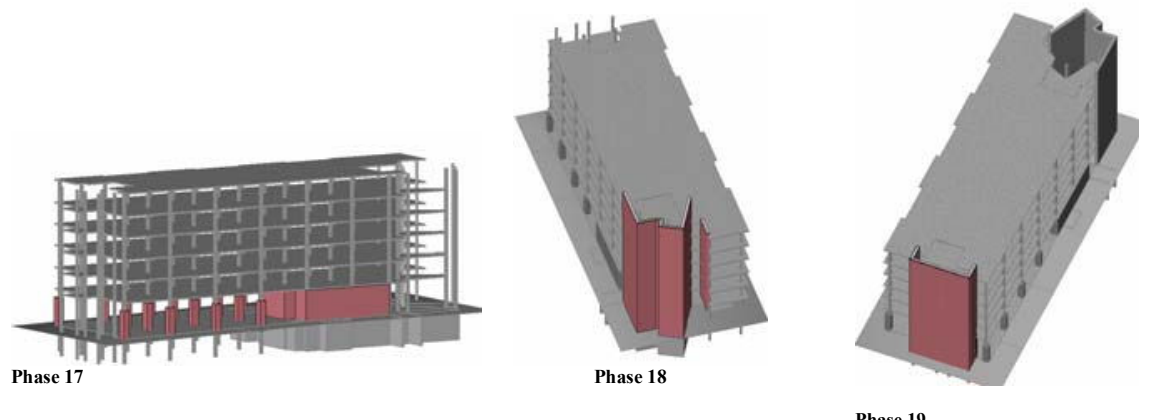

Figure 7. Assignment 6 - Revit Building, Phasing and Schedules

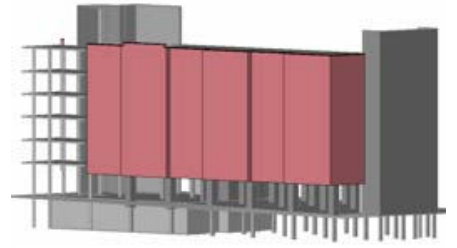

Phase 20

\section{Classroom Sessions - Industry Presentations}

In addition to the hands-on modeling portion of the coursework, the instructors sought to expose the students to the local industry practices regarding BIM. Therefore, a number of key figures in the local AEC industry were invited to make presentations to the class on their organizations' use of BIM in practice, views on the current state-of-BIM and opinions on where they felt the industry was headed. Speakers from the following local-area companies or organizations gave presentations: Eppstein Uhen Architects (architect), Findorff (contractor), University of Wisconsin Facilities Planning and Management Department (owner), Arnold and O-Sheridan (structural engineer), Affiliated Engineers (mechanical systems), JF Ahern (electrical systems), 
Pierce Engineering (structural engineer), CG Schmidt (contractor,) MA Mortensen (contractor), Tekla (BIM software) and Bentley Systems (BIM software.)

These speakers had diverse backgrounds of industry experience. In many engineering courses, guest lecturers would often be engineers themselves, and practicing in the area of the class topic. However, with BIM the concept of integrated practice is fundamental to the BIM design methodology. Therefore getting input from the four participants in this process - architects, engineers, contractors and owners - is necessary to give students a complete picture of how the BIM design methodology is meant to be implemented.

The often overlooked participant in this group is the owner. There has been significant movement by the federal government and major corporations to utilize BIM. But, finding local owners sophisticated enough to be pioneering BIM has been difficult. To be sure, the owner's perspective must be presented or thoroughly addressed within a BIM course to give students the complete picture of the potential of BIM.

Due to the nature of the integrated practice concept, some of the areas covered by guest speakers tended to overlap. This was especially true for the spring 2007 semester, but for the fall 2007 semester an attempt was made to control this problem through enhanced instructor coordination of the speakers. Specifically, the instructors would contact guest speakers around a week prior to their talk and inform them of what previous lecturers had covered and where the class was. This helped lessen, but did not alleviate, guest speakers covering the same material and even showing the exact same graphics. This aside, the guest speakers for our classes can generally be divided up into five categories. These categories are listed below with author comments on what each specifically added to the class.

\section{Architects}

Architects seemed to have provided the best overview of the current state-of-BIM. By de facto standard architects have oversight in new construction from concept to turn-over. Therefore they have proven very good at giving a balanced overview of the potential of BIM and the BIM methodology from start to finish. Architects are well suited to being the first speaker of the semester for a new class of students.

\section{Engineers}

Engineering speakers tended to be from the structural or mechanical disciplines, and generally addressed three types of issues in their presentations. One focus was on technical issues of BIM software and its compatibility with favored analysis packages. A second topic was the workflow changes within the office that BIM necessitates, and finally, project success and failure stories. Speakers who work on the front lines of design firms tended to be more engaging speakers for this level of a class. Several front office speakers focused their talks on profit, loss and the cost of implementing BIM. While these topics are important, the students seemed to find them less valuable.

\section{Contractors}

Contractors proved to be some of the most enthusiastic speakers. They are very happy to relate the construction management and estimating progress BIM technology has allowed them to 
make. The time and money savings of clash detection with tools such as NavisWorks by JetStream was also a unified theme. The contractors' presentation topics proved to be very flexible in terms of where they fit in with the course curriculum. They were equally as valuable in the Construction Management portion as in the Architectural module.

Owners

As previously discussed, owners are a key component to showing students the whole picture. UW-Madison is fortunate to have a BIM savvy owner in our own university's Facilities Planning and Management Department. This owner envisions having the whole campus in a BIM of some form in the future. With the size of our campus this is ambitious, but the speaker was able to convey the near term benefits and realistic goals for this vision. Based on this experience, talks by owners should come in the first portion of the class, but only after students have had a background on the state-of-BIM.

\section{Software Companies}

There currently are a handful of software companies producing BIM programs. The course instructors invited several of the major companies to speak and demonstrate their products. The major caveat imposed was that this was not a sales call. The speakers were asked to speak more to how their company sees the state-of-BIM, what their current product offerings do well and where they see their products going in the future. Based on student response, seeing what else is on the market was interesting and beneficial.

The instructors found that coordinating these guest speakers and their areas of expertise to match the course schedule proved challenging. This may seem like an obvious issue, but attempting to coordinate many of these busy professionals on specific dates and class periods proved to be challenging. During the spring 2007 semester the course schedule, with regards to guest speakers, was constantly evolving. This led to confusion and an inconsistent class periods week to week.

During the fall 2007 semester, three best practices emerged. The first was to schedule all of the speakers prior to the semester beginning. With the heavy use of electronic scheduling devices, computer programs and old-fashioned paper planners, scheduling months in advance was a simple matter and actually appreciated by the speakers. The second practice was, in lieu of asking them to be available on a single date that corresponded to a particular topic, to provide the speakers with several dates within a module in which they could choose an open date. This simplified the scheduling from a drawn out back and forth exchange of dates and topics to less than two hours of phone calls and E-mails. Lastly, once the schedule was established instructors contacted the speakers the week prior to their talk. The main purpose of the conversation was to update the speaker as to what had been covered by other speakers to avoid overlap with previous speakers.

\section{Assigned Technical Readings}

As previously mentioned, there was no textbook assigned for this class. This was due to the fact that during the 2007 school year the authors found no suitable, established text for BIM instruction in publication. Therefore, the instructors elected to utilize a variety of Autodesk BIM 
technical white papers and technical articles from other industry-leading organizations and publications. The readings explored the definitions, concepts, theories and real-world applications of BIM. These readings also addressed other important global topics such as sustainable design and building performance related to LEED certification. The intent of the readings was to introduce not only the practice of using BIM software, but also the theory and concepts of integrated practice in the building design and construction industry. The readings were selected in order to give the students insight into the potential uses and benefits of BIM and integrated practice, and also to educate them about the current state of practice and the implementation difficulties that remain to be overcome. The authors felt it extremely important to give the students an understanding that BIM tools are only really useful in the context of a change in the process of the building design and construction industry. A list of the readings assigned for the fall 2007 semester is given in the Course Reading List Bibliography ${ }^{8-36}$.

Subsequently, each week students were assigned a reading from these sources and asked to respond to a number of specific questions related to the reading assignment. A mix of subjective and objective questions was asked. The authors felt it important to give the students both types of questions to engage them in an understanding that BIM is not just about learning to use the software tools available. It was also an essential goal that the students understand both the professional and financial issues related to the paradigm shift towards BIM in the AEC industry.

While the collection of articles used for the current BIM instruction at the UW has served a valuable role, several new textbooks are slated for release in early 2008 . These texts include the BIM Handbook by Eastman, Teicholz, Sacks and Liston and Building Information Modeling (BIM) by Kymmell. The authors look forward to reviewing these texts and possibly shifting in part or whole towards one of these texts for future BIM instruction.

\section{Final Projects}

In the final part of the course the students were required to complete an independent BIM project. The following final projects were submitted and presented by the students in the spring of 2007 and fall of 2007.

Spring 2007 Topics

- Ogg Residence Hall MEP-BIM Integration

- Construction of an Engineering Hall Model through Workgroups

- Robot Millennium Structural Analysis of Revit Structure Models

- Comparison of Traditional Estimating Techniques vs. BIM-aided Estimating

- 3D Coordination with NavisWorks JetStream

- Integrating a Revit Model into Green Building Studio

- Ram-Revit Link v. 2.0

- Use of REVIT with SAP 2000 as a Software Tool for Adding Value to Analyzing a REVIT Structure Model

- Demonstration of the Compatibility Between Revit and Civil3D

- Dayton Street Residence Hall Project Phasing

- Using Revit With Google Earth and Google SketchUp

- Parametric Objects: Take the Good with the Bad 
Fall 2007 Topics

- Four-Dimensional Modeling Using AutoDesk Revit Building 9, Microsoft Project 2007, and NavisWorks JetStream 5.3

- Importing a Topographic Surface from Civil 3D into Revit

- Integration of Revit and Halo

- Rudimentary BIM Design With Energy Analysis - Utilizing Revit Building 9 with Green Building Studio

- Cost Estimation and Project Planning with Revit

- Importing Google SketchUp to Revit Building

The following pages give some examples of student projects from the first two semesters of the course. Figure 8 shows graphics from an example project titled "Comparison of Traditional Estimating Techniques vs. BIM-aided Estimating.” This project had students using traditional RS Means estimating versus takeoffs and counts generated from Revit.
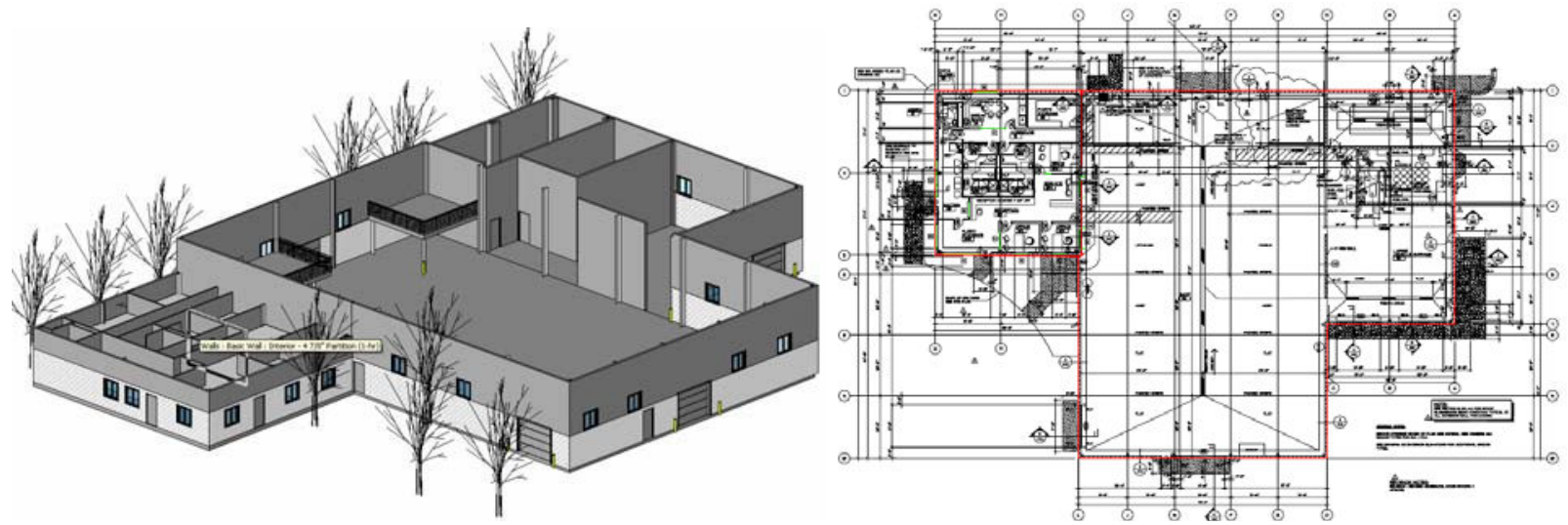

Figure 8. Student Project - Estimating with BIM (Images courtesy of student J. Olson).

Figure 9 shows graphics from a project titled "Integration of Revit and Halo" In this project students created a rudimentary BIM model in Revit, as seen in the background of the figure, and transferred it as a playable map into a HALO game engine.

Figure 10 shows two PowerPoint slides from the student presentation of "Cost Estimation and Project Planning with Revit." In this project students used Revit combined with estimating and scheduling software, as well as several advanced 3D rendering packages.

Figure 11 presents images from a student project titled "Ram-Revit Link v. 2.0." In this project the student explored the issues related with passing a Revit model between Revit Structure and RAM Structural System. Shown in the figure is the structure as rendered by Revit Structure and the same structure as rendered by RAM Structural System. 


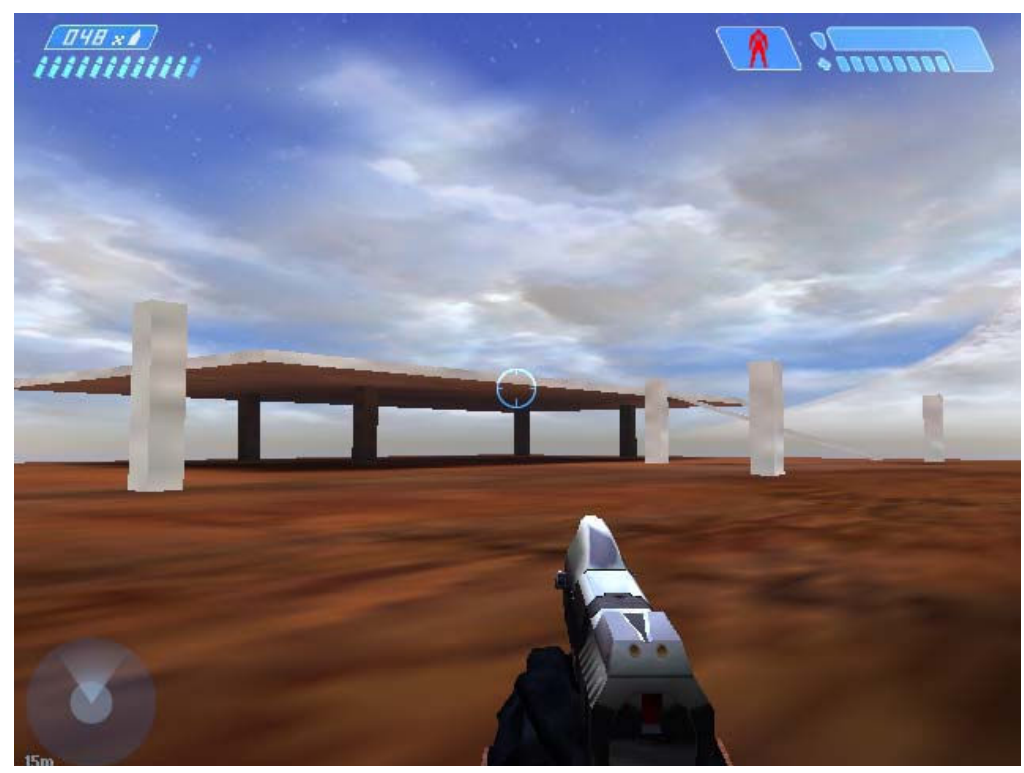

Figure 9. Student Project - "Integration of Revit and Halo" (Image courtesy of students D. Fredrickson, A. Swaner, and B. Rades).
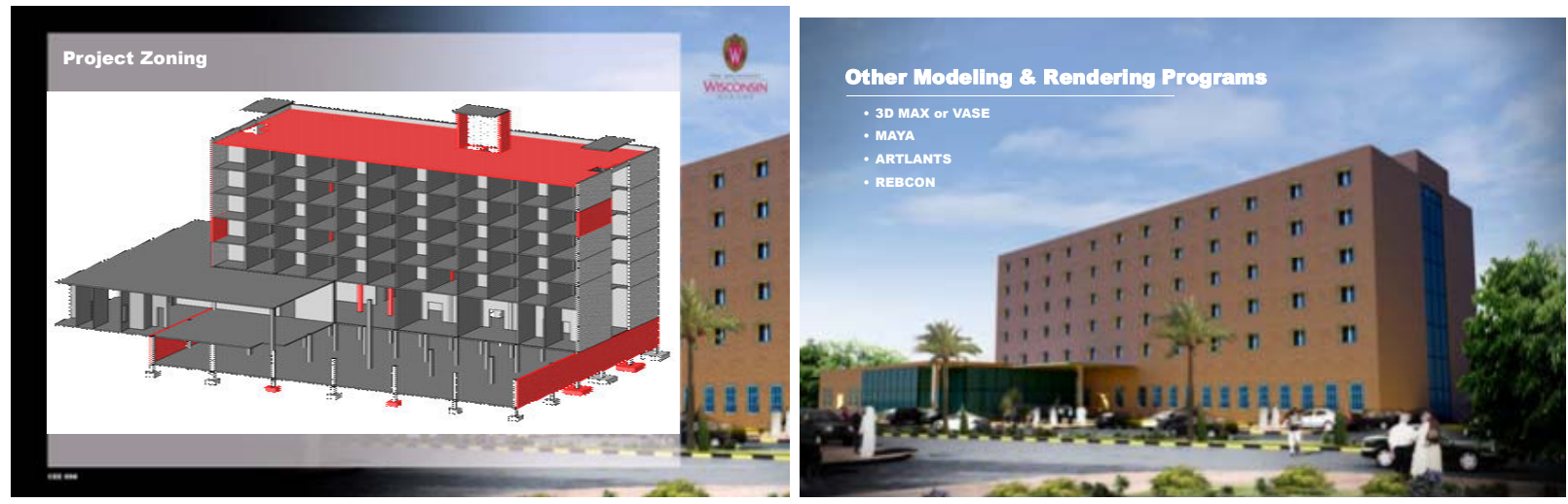

Figure 10. Student Project - "Cost Estimation and Project Planning with Revit" (Images courtesy of students S. S. Mikhail, H. Yoon, and D. Cho).
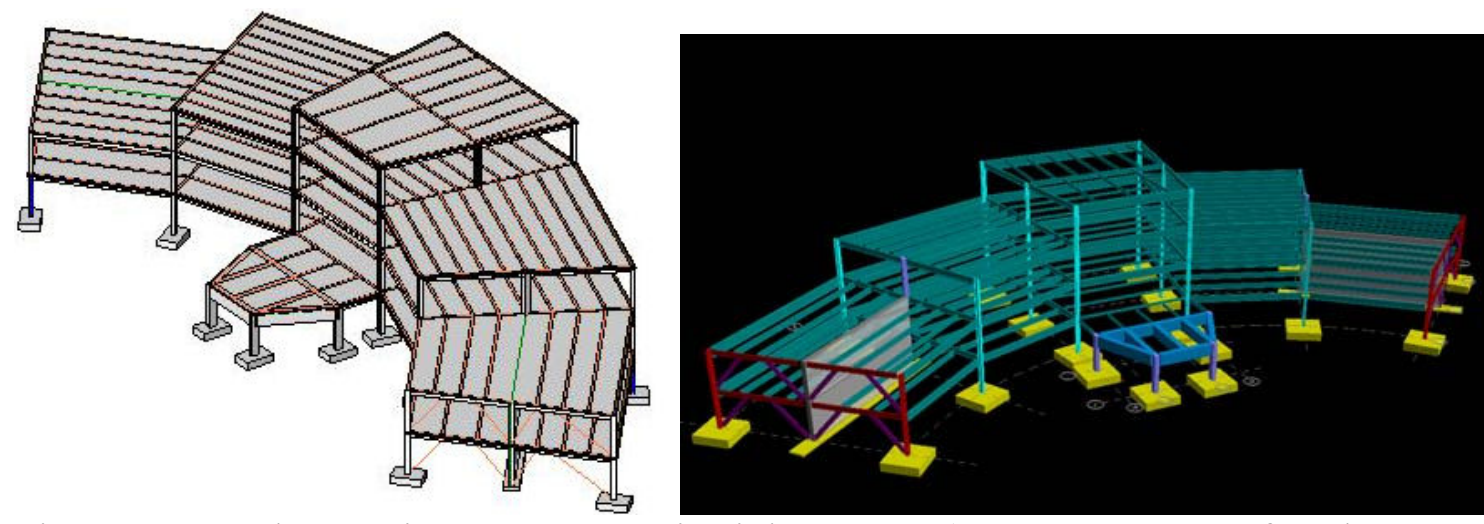

Figure 11. Student Project - "Ram-Revit Link v. 2.0." (Images courtesy of student A. McGraw). 
As can be seen by the topics covered and the sample images, the students did some impressive work for an entry level class. In reviewing the work done between the two semesters several of the topics covered where very similar. However, the instructors feel that the quality and depth of work produced was better for the second, fall 2007 semester. The authors feel that two changes led principally to this improvement.

The first issue was group size. Groups were enlarged from groups of one or two members in the first semester to groups of two to four members for the fall semester. Lowering the workload on each student led to greater collaboration for a higher quality project. This conclusion is not surprising. But in the one group larger than three students, it appeared to the instructors that there was an uneven distribution of work. While this is difficult to accurately quantify, it suggests that the optimum group size for these projects was three students.

A more enlightening conclusion was the instructor's active encouragement, in the fall semester, for students to utilize help files and online forums to answer questions. This appears to have imparted a better sense of self-reliance on the part of the students. Therefore they were better able to go out and teach themselves what they needed to complete their projects. This is critical as these projects are intended to push the students outside the boundaries of what is taught in class.

\section{Assessment of Student Performance}

Students were graded on a conventional A to F scale. This was not a Pass/Fail course. The percentage of points assigned per item was as follows: Attendance and Class Participation $(10 \%)$, BIM modeling assignments (30\%), BIM readings and written responses $(30 \%)$, Final group project (30\%). The project grade consisted of an in-class presentation $(20 \%)$ and a 10 page written report $(80 \%)$. Students performed very well in the class, the vast majority earning As or ABs. Clearly the students devoted significant time to the class, possibly more than the 2 credit value assigned to the class. However, the authors feel that this was appropriate. The learning curve on the software is steep and the academic/intellectual content does not justify a 3 credit course value.

\section{Lessons Learned}

The main lessons learned from the two offerings of the course are summarized in the following bullet points:

- Industry speakers are crucial for bringing in the latest information about industry successes and problems with BIM;

- A course text book, while desirable, was not necessary for successful instruction;

- Mechanical systems modeling homework, based on difficulties with Revit Systems/MEP and student feedback, will be dropped from the spring 2008 curriculum. However, Revit systems/MEP will be demonstrated in class and guest lecturers from these industries will continue;

- Current BIM programs are not perfect. Instructors must be flexible and prepare students for incompatibilities, particularly when students attempt to incorporate popular design software with BIM models in their term projects; 
- Term projects proved very useful in motivating students to explore the potential of BIM technologies;

- Making a distinct effort to demonstrate help files and online help forums to students appears to have given them an advantage when they needed to quickly teach themselves how to use and integrate new software in their term projects. This will be important as students go forward and use other software or newer versions of Revit;

- Amount of 3D modeling may have been too much for students for the number of credits given ( 2 credits/ 3 hours per week class time);

- Reference books or existing curricula for technical learning would have been helpful;

- Students requested more frequent feedback; and

- Questions related to readings could be structured better for assessing the students' understanding of the material.

\section{Conclusions}

Based on the hands-on experience of offering a Building Information Modeling course to Civil Engineering students in a Bachelors of Science degree program it can be concluded that there is indeed substantial learning that takes place in such a course both by the students and instructors. It is important to emphasize that more than the "hands-on" skills gained with a BIM program, the course served to introduce the students to the importance of computable information and how this technology can benefit the construction industry. In fact, it soon became clear to both the students and the instructors that the excitement produced in the class was not from learning the modeling tool itself but from the intellectual exercise of trying to understand why it was important and how best it could be used in the future to improve the AEC industry. In this respect the student projects were a crucial part of the learning experience. Students were forced to grapple with the limitations of many of the software packages they used and in many cases first-generation APIs that did not function as intended or expected. An additional and somewhat unexpected benefit of the class was the fact that many students came to the realization that although they were Civil Engineering students, many of them had very, very little understanding of the actual materials, products and components that make up a building and how the different professionals in the AEC industry interact. Engineering students completing the BIM course had a much better understanding of the role that architects play in the design and construction process. Hopefully, this will result in them having much more effective careers in the AEC industry in the future.

\section{Acknowledgements}

The authors would like to thank all of the industry speakers who participated in the course during the spring 2007 and fall 2007 offerings. In addition, the support provided by the University of Wisconsin Facilities Planning and Management Department and Autodesk Inc was greatly appreciated. Thanks also go to Professor Jeffrey Russell, Chair of the Department of Civil and Environmental Engineering, for enthusiastically supporting the introduction of the BIM course. 


\section{References}

[1] Holness, G. V. R. (2006). "Future Direction of the Design and Construction Industry: Building Information Modeling.". ASHRAE Journal 48 (8). 38-40, 42, 44-6.

[2] Tulacz, G. J. (2007). “The Top 500 Design Firms.” Engineering News Record. 258 (15). 42-4, 46, 48, 50, 52-3.

[3] BIM Forum (2008), BIM FAQ, http://www.bimforum.org/index.php?option=com content\&task=view\&id=19\&Itemid=38\#Q2. Accessed $2 / 27 / 08$.

[4] National Institute of Standards and Technology (2006). National BIM Standard. http://www.facilityinformationcouncil.org/bim/faq.php\#faq1. Accessed 2/27/08.

[5] American Institute for Architects (2007). Integrated Project Delivery: A Guide. http://www.aia.org/SiteObjects/files/IPD_Guide_2007.pdf. Accessed 2/27/08.

[6] Greenwold, Simon (2004). Building Information Modeling with Autodesk Revit Architecture. Autodesk. http://students6.autodesk.com/ama/orig/RAC-2008-CurriculaLectureNotes_Final.pdf. Accessed 1/12/08.

[7] Autodesk (2006). Revit Building 9.1 User's Guide. http://revit.downloads.autodesk.com/download/9 1/HelpBuildingENU.pdf. Accessed 8/14/07.

[8] AGC (2006). "The Contractor's Guide to BIM" Edition 1. pg 10-24.

[9] AIA California Council (2007). "Integrated Project Delivery: A Working Definition" Integrated Project Delivery, McGraw-Hill Construction, New York.

[10] Autodesk (2005). "Multi-User Collaboration with Autodesk Revit Worksharing" Autodesk Revit White Paper. http://images.autodesk.com/adsk/files/Multi User_Collaboration_Revit 8-10.pdf. Accessed 01/12/08.

[11] Autodesk (2005). "Building Information Modeling for Sustainable Design," Autodesk Revit White Paper. http://images.autodesk.com/emea nw_w main/files/bim.pdf. Accessed 01/10/08.

[12] Autodesk (2006). "Autodesk Revit Systems: BIM for MEP Engineering," Autodesk Technical White Paper. http://images.autodesk.com/adsk/files/revit_mep_bim_for_mep_engineering.pdf. Accessed 01/15/08.

[13] Autodesk (2007). "Coordination Between Revit Structure and Revit Architecture," Autodesk Technical White Paper.

http://images.autodesk.com/adsk/files/coordination_between_revit_structure_and_revit_architecture.pdf. Accessed 01/11/08.

[14] Autodesk (2007). "AutoCad Revit MEP Suite Questions and Answers"

http://images.autodesk.com/apac_sapac_main/files/acad_revit_mep_suite2008_qanda.pdf. Accessed 01/08/08.

[15] Autodesk (2007). "Parametric Building Modeling: BIM's Foundation," Autodesk Technical White Paper http://images.autodesk.com/adsk/files/bim_parametric building_modeling_jan07_1_.pdf. Accessed $01 / 15 / 08$.

[16] Autodesk (2007). "Revit Structure and BIM" Autodesk Technical White Paper. http://images.autodesk.com/adsk/files/revit_structure_and_bim.pdf. Accessed 01/16/08.

[17] Autodesk. (2007). "Building Information Modeling in Practice," Autodesk Technical White Paper http://images.autodesk.com/apac grtrchina main/files/bim in practice.pdf. Accessed 01/10/08.

[18] Bedrick, Jim (2005). "BIM and Process Improvement" AECbytes Viewpoint, 20. http://www.aecbytes.com/viewpoint/2005/issue_20.html. Accessed 01/05/08.

[19] Bernstein, Phillip G. and Pittman, Jon A. (2004). "Barriers to the Adoption of Building Information Modeling" Autodesk Building Solutions White Paper.

http://images.autodesk.com/adsk/files/bim_barriers_wp_mar05.pdf. Accessed 12/20/07.

[20] CADinfo.net (2006). "Industry-First Product Combines the Power of Google Earth with Autodesk Revit," http://www.cadinfo.net/pr/060627-ae-avatech.htm. Accessed 01/05/08.

[21] Cyon (2003). "The Building Information Model: A Look at Graphisoft's Virtual Building Concept" Cyon Research Paper. January 2, 2003. www.cyonresearch.com. Accessed 01/16/08.

[22] Dean, Robert Paul and McClendon, Susan (2007). "Specifying and Cost Estimating with BIM" Archi Tech. 10 (3). $49-54$.

[23] Elvin, George (2007). "Communication and Building Information Modeling." Integrated Practice in Architecture Wiley, Hoboken, NJ.

[24] KFA (2005). “Tech Tips: What We Suggest About Autodesk Revit Building” http://www.kfainc.com/techtips/technotesrevit.htm. Accessed 01/11/08. 
[25] Khemlani, Lachmi (2005). "Multi-Disciplinary BIM at Work at GHAFARI Associates," AECbytes Feature. Nov. 21. http://www.aecbytes.com/feature/2005/Ghafari_study.html. Accessed 01/16/08.

[26] Lipman, Robert R. and Reed, Kent A. (2003). "Visualization of Structural Steel Product Models" Itcon Vol 8. 51 - 64. www.itcon.org/2003/5. Accessed 01/12/08.

[27] National Institute of Building Sciences Facilities Information Council (2006). "Building Information Model Overall Scope." National Building Information Model Standard. Pg 19-26.

[28] NavisWorks (2007). Dynamic Virtual Construction. Vendor Literature. http://www.navisworks.com. Accessed 01/04/08.

[29] Pressman, Andrew (2007). "Integrated Practice in Perspective: A New Model for the Architectural Profession" Architectural Record, May. http://archrecord.construction.com/practice/projDelivery/0705proj-1.asp. Accessed 01/15/08.

[30] Roberts, Huw W. (2004) The Importance of Parametrics in Building Information Modeling" AECbytes Viewpoint, No. 5. http://www.aecbytes.com/viewpoint/2004/issue 5.html. Accesed 01/11/08.

[31] Rundell, Rick (2006). "1-2-3 Revit: BIM and Cost Estimating, Part 1," Cadalyst. http://aec.cadalyst.com/aec/article/articleDetail.jsp?id=363582. Accessed 12/15/07.

[32] Rundell, Rick (2006). "1-2-3 Revit: BIM and Cost Estimating, Part 2," Cadalyst. http://aec.cadalyst.com/aec/article/articleDetail.jsp?id=370035. Accessed 01/03/08.

[33] Rundell, Rick (2007). "1-2-3 Revit: BIM and Project Planning," Cadalyst. http://aec.cadalyst.com/aec/article/articleDetail.jsp?id=408794. Accessed 01/11/08.

[34] Rundell, Rick (2007). "1-2-3 Revit: BIM and Collaborative Project Management” Cadalyst. http://aec.cadalyst.com/aec/article/articleDetail.jsp?id=429693. Accessed 01/11/08.

[35] Williams, Chuck (2006). "BIM, the Integrated Practice Model, ADS, and How They Benefit You" Architectural Data Systems White Paper, September 26.

[36] Woolley, Joshua A. (2007). "Now's the Time for 4D CAD in Construction," Cadalyst. http://aec.cadalyst.com/aec/article/articleDetail.jsp?id=435198. Accessed 01/12/08. 